\title{
AVALIAÇÃO INTEGRADA AO PROCESSO ENSINO-APRENDIZAGEM EM CIÊNCIAS: UMA PROPOSTA APLICADA AOS ANOS FINAIS DO ENSINO FUNDAMENTAL ${ }^{1}$
}

\author{
Paula Bernardes Braga ${ }^{2}$ \\ Andressa Giarola Alves
}

\begin{abstract}
RESUMO
Neste trabalho, discutimos a avaliação como parte do processo ensino-aprendizagem. Até a década de 80, as provas escritas, sendo elas discursivas ou objetivas, eram o elemento central do processo de avaliação, sendo consideradas o único método para se avaliar. Porém, a partir da década de 90, a comunidade educacional começou a perceber que a avaliação deveria ir além do seu caráter classificatório passando a ser um procedimento diagnóstico e somativo. Para isso, a avaliação deve estar aliada aos processos de ensino e aprendizagem, sendo um processo bem mais abrangente denominado Ensino-Aprendizagem-Avaliação (ONUCHIC; ALLEVATO, 2011). Dessa maneira, faz-se necessário repensarmos as práticas em sala de aula e buscarmos alternativas que integrem esses três importantes mecanismos. Nesse sentido, o objetivo do presente trabalho foi verificar a funcionalidade de um método de avaliação que promova a aprendizagem dos alunos. Relatamos uma experiência de avaliação realizada com alunos dos anos finais do Ensino Fundamental, utilizando a Avaliação por observação com intervenção imediata no ensino de Ciências aliada ao método de Resolução de problemas. Apesar desse método de avaliação ainda ser pouco utilizado, principalmente no Ensino fundamental, concluímos que é uma metodologia eficaz de avaliação que pode ser utilizada na promoção da aprendizagem, inclusive no ensino de Ciências.
\end{abstract}

Palavras-chave: Avaliação. Ensino-Aprendizagem-Avaliação. Resolução de problemas.

\section{INTEGRATED EVALUATION OF THE TEACHING-LEARNING PROCESS IN SCIENCE: A PROPOSAL APPLIED TO THE FINAL YEARS OF ELEMENTARY SCHOOL}

\begin{abstract}
In this article, the evaluate as component of the teaching-learning process was discussed. Until the 1980s, written tests (whether discursive or objective), were the central element for the evaluation process, being considered the unique method for this purpose. However, from

\footnotetext{
${ }^{1}$ Como citar este artigo: BRAGA, P. B.; ALVES, A. G. Avaliação integrada ao processo ensino-aprendizagem em Ciências: uma proposta aplicada aos anos finais do Ensino Fundamental. ForScience, Formiga, v. 8, n. 1, e00716, jan./jun. 2020. DOI: 10.29069/forscience.2020v8n1.e716.
}

\footnotetext{
${ }^{2}$ Autor para correspondência: Paula Bernardes Braga, e-mail: paulabernardesb@gmail.com
} 
the 90's, the educational community realized that the evaluation should overcome its classificatory character, becoming a diagnostic and summative procedure. For this purpose, the evaluation must be connected to the teaching and learning processes, as a much more comprehensive process, namely Teaching-Learning-Assessment (Onuchic; Allevato, 2011). In this sense, it's necessary to rethink classroom practices, and look for alternatives that could integrate these three important mechanisms. In this way, the aim of the present paper was to verify the functionality of an evaluation method, which could promotes students learning. It was reported an evaluation experience with the final years of Elementary School students, using the Observation Assessment with immediate intervention in the Sciences teaching, associated to the Problem Solving method. Although this evaluation method is not largely used, mainly in Elementary School, this assessment methodology was reported as effective, which can be employed to promote learning, including in Science teaching.

Keywords: Evaluate. Teaching-Learning-Assessment. Problem Solving method.

\section{INTRODUÇÃO}

A avaliação é um importante mecanismo, principalmente quando é parte integrante do processo ensino-aprendizagem. Assim como os diversos componentes do processo educacional, ela vem sofrendo diversas modificações a partir das décadas de 80 e 90 com o surgimento das teorias críticas. Guba e Lincoln (1989) definiram algumas gerações a respeito da avaliação no século XX, sendo a última a geração da ruptura, ou seja, que rompeu com os métodos tradicionais somativos e classificatórios de se avaliar, buscando torná-los formativos e qualitativos.

A década de 90 foi marcante para essa ideia de ruptura; Luckesi (1991) em seu livro “Avaliação da Aprendizagem Escolar" fez uma importante crítica sobre o que ele denominou de "terrorismo homeopático", onde os professores utilizavam a avaliação como um mecanismo de poder e regulação da disciplina na sala de aula. Uma ideia clara de como a avaliação pode ser utilizada como um método punitivo, que pouco acrescentaria na promoção da aprendizagem dos alunos.

Segundo French (2005), a avaliação deve fazer parte do planejamento de ensino e aprendizagem, assim, o professor deve se concentrar em como seus estudantes aprendem, dessa maneira, os alunos devem receber orientações construtivas de como podem melhorar, o que estimularia nos alunos a capacidade de autoavaliação de modo que possam se tornar reflexivos e autônomos.

Segundo Pironel e Onuchic (2016), ensino e aprendizagem são processos distintos, sendo que um pode ocorrer sem que o outro também aconteça. Porém, na sala de aula, o docente visa à aprendizagem do aluno como consequência do ensino e quando unimos esses 
dois processos temos a palavra Ensino-Aprendizagem. Com a avaliação esse pensamento não pode ser diferente. Assim, podemos pensar da seguinte forma: o ensino promove a aprendizagem, a avaliação pode sim ser um diagnóstico do processo de ensino, mas ela deve estar também integrada ao processo de aprendizagem, formando um processo maior e mais complexo denominado Ensino-Aprendizagem-Avaliação (PIRONEL, 2002; ONUCHIC; ALLEVATO, 2011).

De acordo com Sierra (2017), a Resolução de Problemas é um método que visa instigar os alunos na busca e apropriação de estratégias adequadas para que respondam tanto perguntas escolares quanto questões cotidianas. Esse método consiste na apresentação de situações abertas e sugestivas que exijam dos alunos uma atitude ativa ou um esforço para buscar suas próprias respostas, seu próprio conhecimento (SOARES; PINTO, apud POZO; ECHEVERRÍA, 1988). Portanto, essa metodologia demanda do aluno uma carga cognitiva e motivacional maior do que em outras metodologias.

Pironel e Onuchic (2016) demonstraram em seu trabalho uma importante alternativa de avaliação que integra ensino, aprendizagem e avaliação, utilizando o método de Resolução de Problemas. Porém, em sua metodologia eles utilizaram alunos do Ensino Superior e buscavam a aprendizagem de conceitos matemáticos.

Diante do exposto, o trabalho tem como investigar a funcionalidade desse mesmo método denominada Avaliação por observação com intervenção imediata com alunos dos anos finais do Ensino Fundamental na aprendizagem de conceitos de Ciências.

Segundo Onuchic (1999), durante avaliação por observação com intervenção imediata, o papel do professor muda de comunicador de conhecimento para o papel de observador, organizador, mediador, interventor e incentivador da aprendizagem. Dessa forma, ao observar e intervir o professor assume a posição de avaliador do processo de ensino-aprendizagem, sendo também um construtor do conhecimento, junto a seus educandos (PIRONEL; ONUCHIC, 2016).

Assim, ao aliar essas duas metodologias, as autoras buscaram ao mesmo tempo avaliar e promover a aprendizagem, sendo o aluno um sujeito ativo no processo, buscando suas próprias respostas, e o professor assumindo o papel de incentivador, desse modo, a construção do conhecimento ocorre de maneira coletiva entre alunos e professor. 


\section{MATERIAL E MÉTODOS}

A atividade foi realizada com 38 alunos das turmas do $6^{\circ}, 7^{\circ}, 8^{\circ}$ e $9^{\circ}$ ano do Ensino Fundamental, da Escola Estadual de Nazaré de Minas, localizada no distrito de Nazaré de Minas, na cidade de Nepomuceno/MG. O distrito encontra-se as margens do lago de Furnas e possui 1051 habitantes (IBGE, 2010). Os alunos foram divididos em grupos de quatro e cinco integrantes, sendo que na turma do $6^{\circ}$ ano, formaram-se três grupos e nas demais turmas dois grupos (Figura 1). Dessa maneira, foi possível comparar o funcionamento da atividade em cada turma e verificar a funcionalidade da mesma para a promoção da aprendizagem.

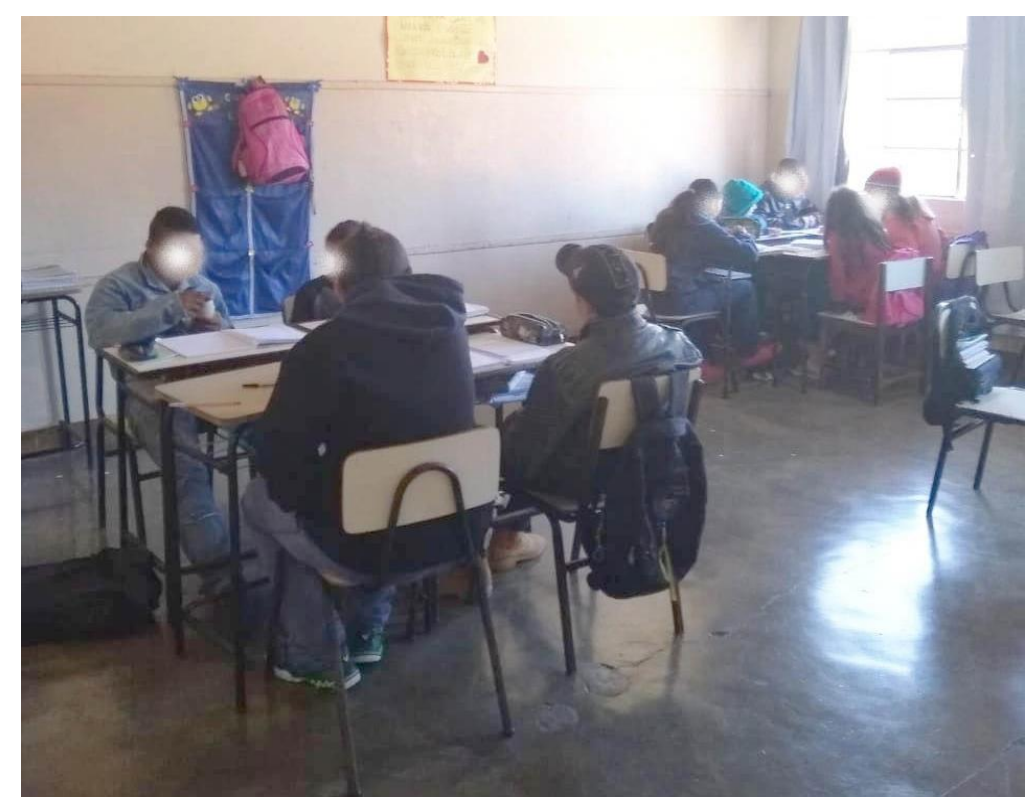

Figura 1 - Disposição dos grupos para a realização da atividade Fonte: Autores (2019).

A professora-pesquisadora observou e documentou por escrito como foi a atividade em cada turma, se houve a participação dos alunos e se com a intervenção eles conseguiram chegar as respostas das questões. Desse modo, utilizamos como metodologia para coleta de dados o diário de campo (Figura 2). 


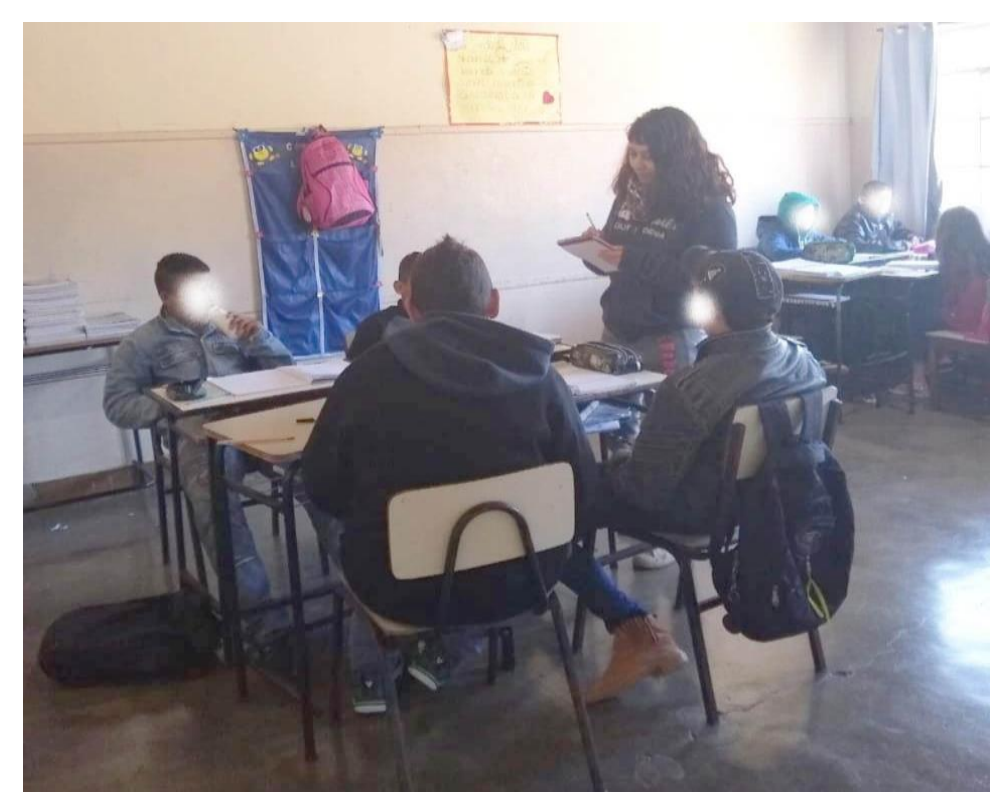

Figura 2 - Registro das informações no diário de campo Fonte: Autores (2019).

De acordo com Lopes (1993), ele é um instrumento complexo, que nos permite atingir amplos objetivos, pois possibilita o registro detalhado das informações, observações e reflexões surgidas no decorrer da investigação ou no momento observado. É um detalhamento descritivo e pessoal sobre os interlocutores, grupos e ambientes estudados.

Posteriormente a divisão das turmas em grupo, iniciamos a avaliação por observação com intervenção imediata no ensino de conceitos de Ciências. Foram propostas situações problemas para que os alunos inicialmente discutissem (nos primeiros 10 minutos), sendo que durante as discussões a pesquisadora observou e relatou no diário a participação de cada aluno e suas reflexões em relação aos problemas.

Depois desse tempo, a professora-pesquisadora realizou a intervenção, aproximandose de cada grupo e discutindo as respostas dadas por eles acerca dos problemas propostos (Figura 3). 


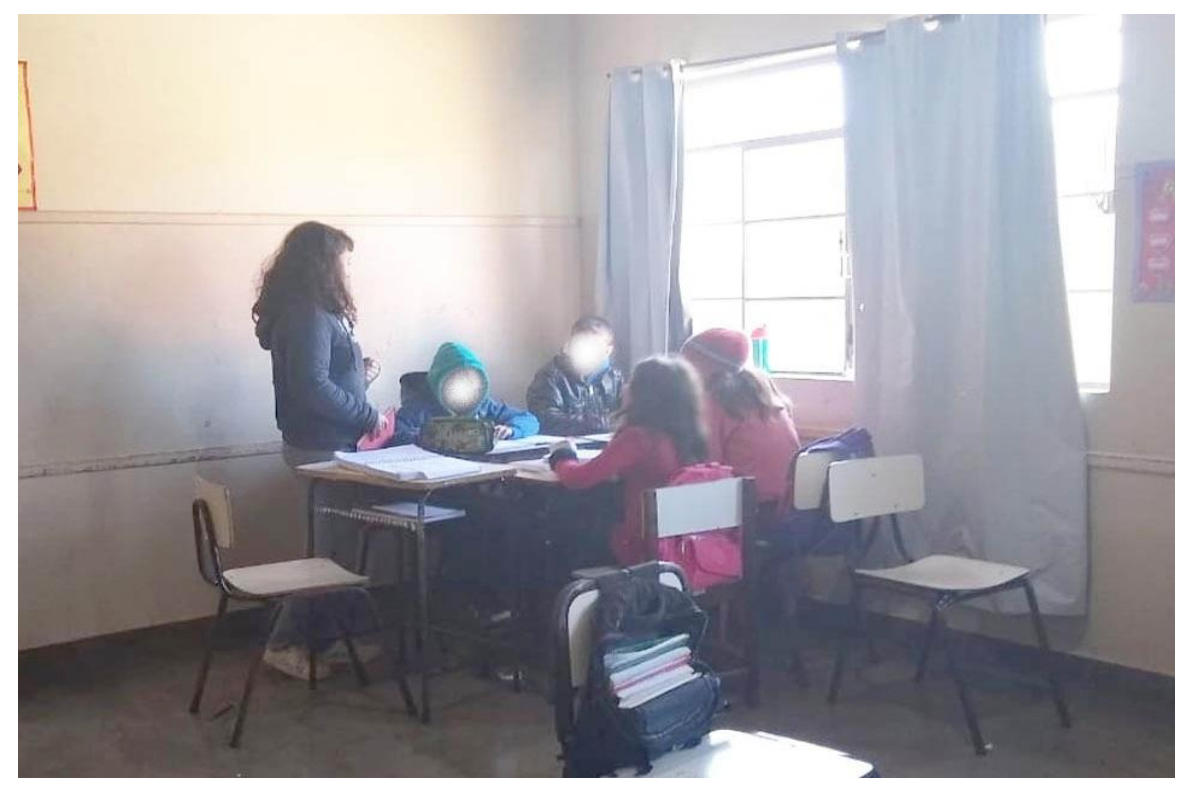

Figura 3 - Intervenção da professora-pesquisadora durante a atividade Fonte: Autores (2019).

Segundo Pironel e Onuchic (2016), a intervenção possibilita a detecção de falhas no processo de aprendizagem e ela pode acontecer na forma de questionamentos, dicas e até por meio da resolução de um problema periférico, diferente do problema gerador trabalhado. Em seguida, os alunos discutiram novamente o assunto em grupo e no final da atividade foi realizada uma discussão geral, com a participação de todos os grupos e da pesquisadora.

Para a seleção dos problemas aplicados em cada turma, consideramos as habilidades básicas referentes a cada ano nos Conteúdos Básicos Comuns (CBC) de Ciências para os anos finais do Ensino Fundamental. Dessa maneira, selecionamos dois importantes temas: Evolução dos seres vivos e Mecanismo de herança.

De acordo com o CBC, para o $6^{\circ}$ ano, uma habilidade básica é "Relacionar informações obtidas através do estudo dos fósseis a características da Terra no passado, seus habitantes e ambientes." Dessa forma, consideramos a seguinte situação problema a ser resolvida pelos alunos: Existem várias espécies que são conhecidas pelos cientistas, mas foram extintas há milhares de anos, como os cientistas sabem que elas existiram? Como eles conhecem suas características, a forma do corpo, hábitos alimentares, entre outras?

O CBC para o $7^{\circ}$ ano considera dos tópicos 14 e 15 as seguintes habilidades básicas "Associar processos de seleção natural à evolução dos seres vivos, a partir de descrições de situações reais." e "Compreender o papel da reprodução sexuada na evolução e diversidade das espécies." Sendo assim, foram propostos os seguintes problemas: As espécies se modificaram e se modificam ao longo dos tempos? Como é possível existirem espécies 
adaptadas aos mais diversos ambientes? Como a reprodução sexuada é importante nessas situações?

Para a elaboração dos problemas propostos na turma do $8^{\circ}$ ano, consideramos a seguinte habilidade básica "Comparar as explicações de Darwin e Lamarck sobre a evolução." Assim, foram elaborados os seguintes problemas: Como os seres vivos evoluem? Por que as girafas possuem o pescoço comprido? Como elas "adquiriram” essa característica?

O CBC para o $9^{\circ}$ ano considera como habilidades básicas no Tema 13- Mecanismo de Herança, as seguintes habilidades "Compreender que o meio ambiente pode alterar o fenótipo de um indivíduo" e, "Associar o processo da hereditariedade como a transmissão de características de pais para seus filhos." Considerando essas habilidades, elaboramos os seguintes problemas: Como o ambiente pode modificar as características dos seres vivos? Por que algumas características são "passadas" de pais para filhos e outras não são?

\section{RESULTADOS E DISCUSSÃO}

No início da atividade, a professora-pesquisadora manteve-se em uma posição de observação. Dessa maneira, foi possível observar como os grupos estavam lidando com a resolução dos problemas propostos e quais estavam com mais facilidade ou dificuldade. Assim, como afirmam Pironel e Onuchic (2016), a divisão de grupos nessa situação, favorece o trabalho do professor, permitindo um melhor andamento da atividade avaliativa.

Essa observação foi possível através das dúvidas apresentadas e das discussões realizadas por cada grupo. Por exemplo, na atividade realizada no $8^{\circ}$ ano ao discutirem sobre como as girafas "adquiriram" a característica do pescoço comprido, alguns grupos discutiam que a característica "estava no sangue" já outros iam mais além e afirmavam que ela estava nas células.

A observação é uma etapa importante da avaliação, pois dessa maneira, o professor pode selecionar quais grupos precisam de mais atenção e definir a ordem com que os mesmos receberão essa atenção, partindo dos que apresentam mais dificuldades.

É nessa etapa que se inicia a intervenção, onde o professor chama á discussão os alunos e verifica de maneira mais objetiva como eles estão se portando frente à resolução dos problemas e se estão no "caminho certo" para resolvê-lo.

A seguir, reproduzimos um diálogo para cada turma entre a professora-pesquisadora e os elementos dos grupos estudados, retirado do diário de campo: 


\section{$6^{\circ}$ ano}

Professora: O que vocês responderam?

Aluno: Os cientistas sabem da existência dessas espécies por meio de restos mortais, ossos.

Professora: Como são chamados esses ossos? Como eles estariam preservados mesmo após tanto tempo? Como por meio desses ossos é possível descobrir as diversas características desses seres vivos?

Aluno: através de DNA, realizando o DNA dos ossos encontrados.

Professora: Será que o DNA é preservado em todos os fósseis? Isso não seria difícil de acontecer com a passagem do tempo? Discutam essas questões, depois voltamos a conversar.

Nesse diálogo, vimos que mesmo sem conhecer o nome "fósseis" os alunos já sabiam o seu significado e também já sabiam que os cientistas os utilizavam para estudar espécies já extintas. Assim, é possível observar como os conhecimentos prévios são importantes durante a aprendizagem.

De acordo com Pozo (1998), é importante que o professor realize atividades que ativem o conhecimento prévio dos alunos. Ainda segundo ele, o docente deve propiciar que esses conhecimentos se articulem às novas informações que estão sendo apresentadas, como podemos observar nos diálogos apresentados. Campos, Bortoloto e Felício (2003) afirmam que quando ocorre essa articulação pode-se considerar que ocorreu uma aprendizagem significativa, e isso acontece através do desequilíbrio provocado pela nova informação, que leva a mudanças conceituais dos conhecimentos pré- existentes.

\section{$7^{\circ}$ ano}

Professora: O que vocês responderam?

Aluno 1: Sim, as espécies se modificam e modificaram ao longo do tempo.

Professora: Como ocorreram essas modificações? Por que, por exemplo, o camelo é adaptado a viver em um ambiente como o deserto.

Aluno 1: Os animais possuem características de acordo com o ambiente em que vivem.

Professora: Mas como essas características surgem?

Aluno 2: Elas surgem da necessidade de sobrevivência daqueles animais.

Professora: Então quer dizer que se você fosse colocado em um deserto seu corpo se adaptaria para sobreviver ali?

Aluno 2: Não, eu morreria.

Professora: Então como o camelo conseguiu as características para sobreviver? 
Aluno 1: Essas características vêm da junção do DNA da mãe e do pai.

Professora: Sim, essa junção de características é importante na Evolução. Mas para ser passada para os filhos ela tem que estar no DNA dos pais, como isso acontece? Discutam e voltaremos a conversar.

No $7^{\circ}$ ano, os alunos já conheciam os conceitos de célula, DNA e reprodução sexuada, mas ainda não tinham trabalhado sobre Evolução. No diálogo com a professora-pesquisadora foi possível observar como eles associaram os conceitos já aprendidos com o conceito de Evolução que estava sendo discutido.

\section{$8^{\circ}$ ano}

Professora: O que vocês responderam?

Aluno 1: Os seres vivos evoluem através das células.

Professora: Mas como através da célula? O que deve acontecer e em qual lugar da célula acontece?

Aluno 2: Deve acontecer alguma mudança no núcleo.

Professora: Isso, mas onde especificamente?

Aluno 2: No DNA.

Professora: Muito bem, mas como essas mudanças ocorrem lá no DNA? Qual o nome damos para essas modificações? Discutam sobre isso e voltaremos a conversar.

Aluno 3: As girafas possuem o pescoço comprido para se alimentar das folhas mais altas.

Professora: Sim, é verdade. Mas como ela conseguiu essa característica?

Aluno 3: Essa característica está nas suas células.

Professora: Mas como essa característica surgiu? Ela é uma característica vantajosa para as girafas? Discutam e voltaremos a conversar.

Já no $8^{\circ}$ ano, como eles já conheciam o conceito de Evolução, imediatamente alguns alunos já o associaram com as células e com o material genético. Por isso, a discussão se deu sobre como a Evolução ocorre, assim a pesquisadora na discussão com a participação de todos pôde trabalhar as teorias Evolucionistas de Lamarck e Darwin.

\section{$9^{\circ}$ ano}

Professora: O que vocês responderam?

Aluno 1: O ambiente modifica o corpo dos seres vivos através do calor, da temperatura.

Professora: Como assim? Quais os tipos de modificação? 
Aluno 1: Modificações genéticas.

Professora: Como essas modificações genéticas ocorrem e onde elas ocorrem? Será que toda modificação ambiental, consegue alterar a genética?

Aluno 2: Acho que não.

Professora: Por exemplo, ao pintar o cabelo eu estou alterando a minha genética? Se eu pintar o cabelo de louro essa característica será passada para os meus filhos?

Aluno 2: Não.

Professora: Por que não?

Aluno 2: Por que você não estaria alterando o seu DNA.

Professora: Muito bem. E por que então algumas características passam de pais para os filhos e outras não? Discutam sobre isso e voltaremos a conversar.

No $9^{\circ}$ ano, também observamos que mesmo sem conhecer os conceitos de Fenótipo e Genótipo, os alunos já sabiam que algumas características estavam no material genético e outras não. Assim, na discussão com a participação de todos foi possível atrelar o significado desses conceitos com o que foi discutido durante a intervenção.

Nos diálogos, durante a observação e a intervenção, foi possível observar a construção das respostas pelos integrantes dos grupos. Como eles partiram das questões mais simples das perguntas para as mais complexas para a resolução dos problemas e como seus Modelos mentais estão organizados acerca dos assuntos tratados nas situações problemas. Dessa maneira, é possível avaliar os alunos.

Foi possível observar como alguns alunos estavam mais familiarizados com os temas e mesmo ainda sem conhecer especificamente os assuntos objetivados nas questões problemas, buscaram os conhecimentos que já tinham para tentar resolvê-las.

É importante lembrar que na realização da Avaliação por observação com intervenção imediata, o professor tem o papel de observador, e quando ele vê necessário a intervenção, essa deve se dar sob a forma de questões, incentivando os estudantes a pensar e buscar os conhecimentos prévios sobre os assuntos tratados.

\section{CONCLUSÃO}

A partir do surgimento das teorias críticas, no século XXI fez-se necessária a mudança de postura dos professores em relação à avaliação, o que foi chamado de geração da ruptura (GUBA; LINCOLN, 1989). Ela é um instrumento que não deve ser usado de maneira 
somativa ou classificatória, mas deve ser formativa e voltada para a aprendizagem dos alunos (LUCKESI, 1997).

A Metodologia de Ensino-Aprendizagem-Avaliação de Ciências através da Resolução de Problemas mostrou-se consonante a essa visão, pois possibilitou a integração dos processos de ensino, aprendizagem e avaliação, ajustados ao currículo escolar.

Além disso, a Metodologia se mostrou alinhada ao processo formativo dos alunos, principalmente por permitir que os mesmos buscassem o conhecimento, dessa forma eles se tornam sujeitos ativos no processo de aprendizagem.

Com a realização do presente trabalho, observamos como a avaliação pode ser integrada ao processo de ensino-aprendizagem e concluímos como é importante que isso ocorra para a aprendizagem dos alunos.

\section{REFERÊNCIAS}

CAMPOS, L. M. L.; BORTOLOTO, T. M.; FELÍ́CIO, A. K. C. A produção de jogos didáticos para o ensino de Ciências e Biologia: uma proposta para favorecer a aprendizagem. Caderno dos núcleos de Ensino, São Paulo, v. 3548, 2003.

INSTITUTO BRASILEIRO DE GEOGRAFIA E ESTATÍSTICA. Censo demográfico 2010: características da população.

FRENCH, D. Resource pack for assessment for learning in mathematics.

Leicester: The Mathematical Association, o e dos domicílios. Rio de Janeiro, RJ. 2011.2005.

GUBA, E. G.; LINCOLN, Y. S. Fourth generation evaluation. Newbury Park, CA: Sage, 1989.

LOPES, M. J. M. Les soins, images et réalités: le quotidien soignant au Brésil. 1993. Tese (Doutorado em Sociologia) - Université Paris, Paris, 1993.

LUCKESI, C. C. Avaliação da aprendizagem escolar. 8. ed. São Paulo: Cortez, 1997.

LUCKESI, C. C. Avaliação da aprendizagem escolar: apontamentos sobre a pedagogia do exame. Tecnologia Educacional, Rio de Janeiro, v. 20, n. 101, 1991.

ONUCHIC, L. L. R. Ensino-aprendizagem de matemática através da resolução de problemas. Pesquisa em educação matemática: concepções e perspectivas. São Paulo, p. 199-218, 1999.

ONUCHIC, L. L. R.; ALLEVATO, Norma Suely Gomes. Pesquisa em resolução de problemas: caminhos, avanços e novas perspectiva. Bolema-Boletim de Educação Matemática, Rio Claro, v. 25, n. 41, p. 73-98, 2011.

PIRONEL, M. A avaliação integrada ao processo de ensino-aprendizagem da 
matemática na sala de aula. 2002. 193 f. Dissertação (Mestrado em Educação Matemática) Universidade Estadual Paulista, Rio Claro, 2002.

PIRONEL, M.; ONUCHIC, L. L. R. Avaliação para a aprendizagem: uma proposta a partir de transformações do conceito de avaliação na sala de aula no século XXI. In CONGRESSO NACIONAL DE AVALIAÇÃO EM EDUCAÇÃO (CONAVE), IV, 2016. Bauru. Anais... Bauru: UNESP, 2016.

POZO, J. I.. Teorias cognitivas da aprendizagem. 3. ed. Porto Alegre: Artes Médicas, 1998.

SECRETARIA DE ESTADO DA EDUCAÇÃO DE MINAS GERAIS. Conteúdo Básico Comum (CBC) de Ciências no EnsinoFundamental da $6^{a}$ a $9^{\text {a }}$ Séries. Belo Horizonte, MG, 2007. Disponível em:

http://crv.educacao.mg.gov.br/sistema_crv/banco_objetos_crv/\%7BBC26290C-C90B-44EF$\underline{866 \mathrm{~A}-}$

10C750F63D7B\%7D_livro\%20de\%20ciencias.pdfhttp://crv.educacao.mg.gov.br/sistema_crv /banco_objetos_crv/\%7BBC26290C-C90B-44EF-866A-

10C750F63D7B\%7D_livro\%20de\%20ciencias.pdf. Acesso em: 03abr. 2019.

SIERRA, C. L. C. O Ensino de ciências por resolução de problemas: uma proposta aplicada a estudantes do Ensino Fundamental da cidade de Araucária. 2017. 95 f. Dissertação (Mestrado em Formação Científica, Educacional e Tecnológica) - Universidade Tecnológica Federal do Paraná, Curitiba, 2017.

SOARES, M. T. C.; PINTO, N. B. Metodologia da resolução de problemas. In: $24^{\text {a }}$ REUNIÃO NACIONAL DA ANPED, 2011, Caxambu. Anais [...] Disponível em: http://www.ufrrj.br/emanped/paginas/conteudo_producoes/docs_24/metodologia.pdf. Acesso em: 03 abr. 2019.

\section{DADOS DOS AUTORES}

\section{Paula Bernardes Braga}

E-mail: paulabernardesb@gmail.com

Currículo lattes: http://lattes.cnpq.br/4080089937095826

Pós-graduanda no Curso de Especialização em Ensino de Ciências nos anos finais do Ensino Fundamental Ciência é 10! pela Universidade Federal de Uberlândia (UFU), especialização em Pós-Graduação em Docência pelo Instituto Federal Minas Gerais (IFMG - Campus Arcos), graduação em Programa Especial de Formação Pedagógica de Docentes - Biologia pela Universidade de Franca (UNIFRAN). Graduação em Ciências Biológicas pela Universidade Federal de Lavras (UFLA). Atualmente é professora efetiva de Ciências/Biologia na Secretaria Estadual de Educação de Minas Gerais (SEE-MG).

\section{Andressa Giarola Alves}

E-mail: andressagiarola@gmail.com

Currículo lattes: http://lattes.cnpq.br/2080487339146515

Mestrado profissional em Mestrado Nacional Profissional em Ensino em Física pela Universidade Federal de Lavras (UFLA). Graduação em Física pela UFLA. Atualmente é professora da Escola Estadual Dom Delfim, professora do Instituto Presbiteriano Gammon e Professora da Pré-Vestibular Admissão. 